\title{
Colour-Doppler sonography of the musculophrenic vein in cows
}

\author{
Braun, Ueli ; Hoegger, R ; Hässig, Michael
}

\begin{abstract}
The goal of the present study was to examine the musculophrenic vein of 29 healthy Swiss Braunvieh cows using colour-Doppler sonography to determine vessel morphology and diameter, and blood flow velocity. The hair over the reticular region was clipped, and the left musculophrenic vein was examined before and $10 \mathrm{~min}$ after sedation using $0.03 \mathrm{mg} / \mathrm{kg}$ xylazine. The musculophrenic vein appeared as a vessel with a diameter of $0.5-1.1 \mathrm{~cm}$ located in the diaphragmatic musculature. The spectral display was a broad band structure with a wave-like shape. The Doppler measurement point was $1.5-2.7 \mathrm{~cm}$ from the body surface. The diameter of the vein and the blood flow velocity did not differ significantly before and after sedation. Before sedation, the mean diameter (+/-SD) of the musculophrenic vein was $0.7(0.2)$ $\mathrm{cm}$, the maximum blood flow velocity $90.2(38.6) \mathrm{cm} / \mathrm{s}$, the mean blood flow velocity $60.4(22.3) \mathrm{cm} / \mathrm{s}$ and the minimum blood flow velocity $41.4(24.2) \mathrm{cm} / \mathrm{s}$. There were significant correlations $(\mathrm{r}=0.45-0.90)$ between blood flow velocity before and after sedation and between minimum, maximum and mean blood flow velocities.
\end{abstract}

DOI: https://doi.org/10.1016/j.tvjl.2007.10.027

Posted at the Zurich Open Repository and Archive, University of Zurich ZORA URL: https://doi.org/10.5167/uzh-3573

Journal Article

Originally published at:

Braun, Ueli; Hoegger, R; Hässig, Michael (2009). Colour-Doppler sonography of the musculophrenic vein in cows. Veterinary Journal, 179(3):451-454.

DOI: https://doi.org/10.1016/j.tvjl.2007.10.027 
Colour Doppler sonography of the musculophrenic vein in

29 healthy cows

U. Braun, R. Hoegger, M. Haessig

U. Braun, DrMedVet, R. Hoegger, DrMedVet, M. Haessig, DrMedVet, Department of Farm Animals, University of Zurich, Winterthurerstrasse 260, CH-8057 Zurich, Switzerland 


\section{Summary}

The goal of the present study was to examine the musculophrenic vein of 29 healthy Swiss Braunvieh cows via colour Doppler sonography to determine vessel morphology and diameter and blood flow velocity. The hair over the reticular region was clipped, and the left musculophrenic vein was examined via colour Doppler sonography before and ten minutes after sedation using $0.03 \mathrm{mg} / \mathrm{kg}$ body weight of xylazine. The musculophrenic vein appeared as a vessel with a diameter of 0.5 to $1.1 \mathrm{~cm}$ located in the diaphragmatic musculature. The spectral display was a broad band structure with a wave-like shape. The Doppler measurement point was 1.5 to $2.7 \mathrm{~cm}$ from the body surface. The diameter of the vein and the blood flow velocity did not differ significantly before and after sedation. Before sedation, the mean diameter of the musculophrenic vein was $0.7[0.2] \mathrm{cm}$, the maximum blood flow velocity 90.2 [38.6] $\mathrm{cm} / \mathrm{s}$, the mean blood flow velocity 60.4 [22.3] $\mathrm{cm} / \mathrm{s}$ and the minimum blood flow velocity 41.4 [24.2] $\mathrm{cm} / \mathrm{s}$. There were significant correlations with correlation coefficients of 0.45 to 0.90 between blood flow velocity before and after sedation and between minimum, maximum and mean blood flow velocities.

\section{Introduction}

The musculophrenic vein is paired and carries blood from the costal part of the diaphragm to the internal thoracic vein. From there the blood travels to the right side of the heart via the cranial vena cava. The musculophrenic vein was of little clinical interest until the introduction of sonography of the reticulum in cattle (Götz 1992, Braun and Götz 1994). When scanning the reticulum, this vein is almost always seen in longitudinal section as a 
prominent hypoechogenic structure in the diaphragmatic musculature a few centimetres from the skin (Götz 1992, Braun and Götz 1994). In cattle with right-sided cardiac insufficiency, compression of the cranial vena cava by intrathoracic masses or inflammation of the diaphragm, changes in the musculophrenic vein are likely, and investigation of this vessel may be of diagnostic importance. Thus, the goal of the present study was to establish a data base by determining the appearance, diameter and blood flow velocity of the musculophrenic vein of 29 healthy cows using B-mode and colour Doppler sonography. The examinations were done on sedated and nonsedated cows because sedation may affect blood vessel diameter and blood flow velocity. The information thus gained is useful for the veterinarian because sedation is commonly required for the examination of cattle (Braun and Föhn 2005).

\section{Materials and methods}

\section{Animals}

Twenty-nine clinically healthy non-gravid Swiss Braunvieh cows ranging in age from two-and-a-half to 8.0 years (mean, 4.6 years) were used. The examinations were carried out between 08:00 and 10:00 $\mathrm{h}$ with the cows standing in stocks. The cows were halter-tied and restrained using a flank fold grip.

\section{B-mode and colour Doppler sonography}

The procedure for B-mode and colour-Doppler sonography has been described in detail elsewhere (Hoegger 2006). A $50 \mathrm{~cm}$ x $50 \mathrm{~cm}$ region over the reticulum was clipped. A 5.0 MHz real-time linear transducer (Hitachi 
Ultrasound scanner EUB 8500) was used to examine the musculophrenic vein twice, starting at the ventral midline and progressing laterally to the left. The transducer was held parallel to the longitudinal axis of the animal. The first examination was done without sedation and the second was carried out $10 \mathrm{~min}$ after intravenous administration of $0.03 \mathrm{mg} / \mathrm{kg}$ xylazine (Rompun, Bayer). The abdominal wall was scanned first, and then the left musculophrenic vein was identified and viewed longitudinally with B-mode. The diameter of the musculophrenic vein was measured electronically after storing of the ultrasonographic image by means of the two cursors from intima to intima of the vessel. Then, the colour-Doppler gate was directed parallel to the wall of the vein to visualise the blood flow and then positioned at a $60^{\circ}$ angle in the centre of the vein. By turning on the pulsedwave colour-Doppler ultrasound instrument, audible sound could be heard and the spectral display was visible on the screen. Optimal colour flow and spectral curve images were frozen on the screen to determine the distance between the Doppler measurement point and the body surface, the diameter of the vein and the maximum, minimum and mean blood flow velocities.

Approval of the study by an ethical committe

The study was approved by an ethical committee of the canton of Zurich, Switzerland.

\section{Statistical analysis}

The statistical analyses were done using StatView 5.1 (SAS Institute, 8602 Wangen, Switzerland). The frequencies, means and standard deviations of all measured variables were determined. Differences between 
measurements were analyzed using an unpaired $t$-test. The range between the $10^{\text {th }}$ and the $90^{\text {th }}$ percentiles was defined as the normal range. Correlations were calculated for measurements obtained before and after sedation and between different flow velocities. $\mathrm{P}<0.05$ was considered significant.

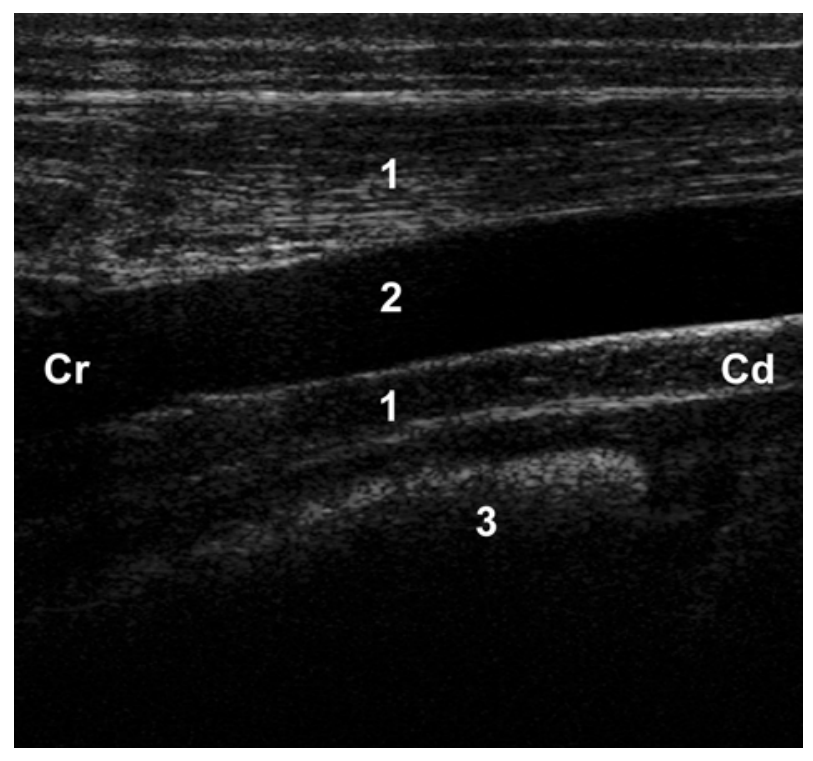

Figure 1: B-mode sonogram of the musculophrenic vein. Die Vena musculophrenica erscheint als echoarmes Gefäss, das in die Muskulatur eingebettet ist. Die Untersuchung erfolgte aus de mit einem 7.5 MHz Linerar transducer. 1 Muskulatur der ......, 2 Musculophrenic vein, 3 Reticulum, 5 Cr Cranial, Cd Caudal.

\section{Results}

Morphological observations with B-mode sonography

The musculophrenic vein could be visualised in all the cows and appeared as a vessel running parallel to the longitudinal axis of the animal within the 
diaphragmatic musculature (Fig 1). The vein was located a few centimetres from the body surface; this distance increased slightly from caudal to cranial because of the anatomical position of the diaphragm. The diameter of the vein varied from 0.5 to $1.1 \mathrm{~cm}$ before and from 0.4 to $1.2 \mathrm{~cm}$ after sedation (Table 1). The mean diameter of the musculophrenic vein was $0.7[0.2] \mathrm{cm}$ before and $0.8[0.2] \mathrm{cm}$ after sedation.

\section{Doppler observations}

The spectral display appeared as a broad band with a wave-like course (Fig 2). The Doppler measurement point was 1.5 to $2.7 \mathrm{~cm}$ (mean [sd], 2.1 [0.5] $\mathrm{cm}$ ) from the body surface. There were no significant differences between measurements before and after sedation (Table 1). The maximum blood flow velocity was 90.2 [38.6] $\mathrm{cm} / \mathrm{s}$ before and 81.3 [30.0] $\mathrm{cm} / \mathrm{s}$ after sedation, the mean blood flow velocity was $60.4[22.3] \mathrm{cm} / \mathrm{s}$ before and $49.9[19.4] \mathrm{cm} / \mathrm{s}$ after sedation, and the minimum blood flow velocity was $41.4[24.2] \mathrm{cm} / \mathrm{s}$ before and $31.1[23.2] \mathrm{cm} / \mathrm{s}$ after sedation.

There were significant correlations $(\mathrm{P}<0.05)$ between the blood flow velocity before and after sedation for the maximum values $(r=0.69)$ and the mean values $(r=0.45)$ but not for the minimum values $(r=0.28)$. There were also significant correlations between the maximum and mean blood flow velocity $(\mathrm{r}=0.90)$, between mean and minimum blood flow velocity $(\mathrm{r}$ $=0.73)$ and between maximum and minimum blood flow velocity $(r=0.63$, $\mathrm{P}<0.05)$. 


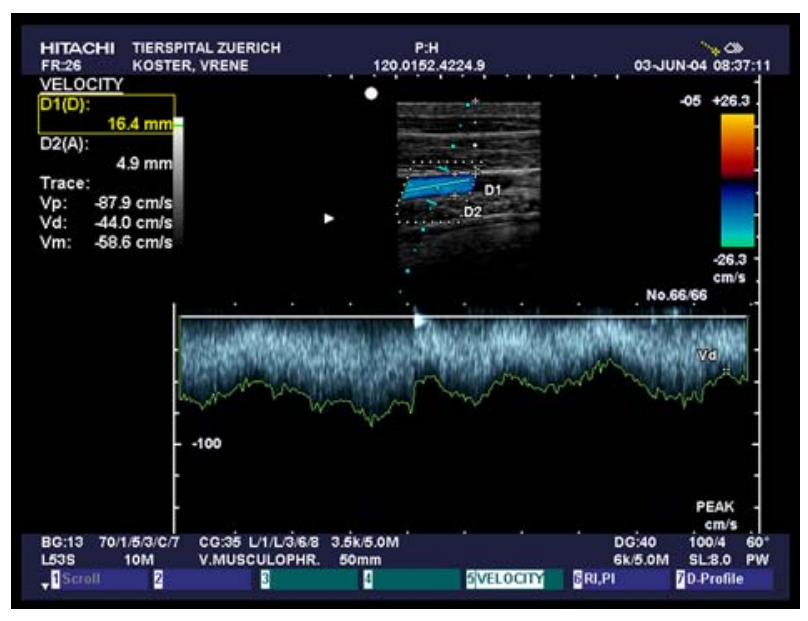

Figure 2: Colour Doppler sonogram of the musculophrenic vein of a threeyear-old Swiss Braunvieh cow before sedation with xylazine. A longitudinal view of the musculophrenic vein with superimposed colour mode is seen at the top and the corresponding spectral display at the bottom.

\section{Discussion}

With the introduction of sonographic examination of the reticulum, which is routinely carried out in cattle with indigestion in our clinic, the musculophrenic vein has become a reference structure. It can be visualised during examination of the reticulum in almost all cases and is particularly well suited to Doppler sonography because of its size and location in the diaphragmatic musculature. The vein is accessible in longitudinal section using a beam angle of $60^{\circ}$ and fulfills all the requirements necessary for colour Doppler sonography of a vein (Widder and Goertler 2004). The superficial position of the musculophrenic vein prevents weakening of the colour signal and large variations in measurements. The accuracy of measurements depends on the type and thickness of the tissue between the transducer and vein (Hendrickx and others 1990, Ranke and others 1990) 
and is adversely affected by fat and muscle tissue. The volume of blood in the musculophrenic vein is also adequate for measurement even though its diameter is smaller than that of the milk vein (Hoegger 2006, Braun and Hoegger 2006) or the jugular vein (Föhn 1992, Braun and Föhn 2005, Hoegger 2006).

Compared with the jugular vein, sonographic examination of the musculophrenic vein is easier. Cows tended to resist sonographic examination of the jugular vein (Föhn 1992, Hoegger 2006), and even slight head movements resulted in substantial measurement errors. Examination of the musculophrenic vein on the other hand was well tolerated by the majority of cows, which were restrained using only a flank fold grip while the examiner sat on a stool. In cows with indigestion, sonographic examination of the reticulum is a routine procedure and therefore the assessment of the musculophrenic vein does not complicate the procedure. Although the milk vein is even easier to locate than the musculophrenic vein, examination is usually limited to cows because of its diameter. Furthermore, pressure applied to the vessels by the transducer can alter the findings for superficial veins, such as the jugular and milk veins. These disadvantages are not encountered during sonographic examination of the musculophrenic vein because it is embedded in the diaphragmatic musculature and is 1.5 to $2.7 \mathrm{~cm}$ from the skin surface. Thus, this vein is located deep enough to avoid pressure from the transducer, but close enough to the body surface that blood flow can be easily detected.

Blood flow velocity is higher in the musculophrenic vein than in either the jugular or milk vein. The maximum blood flow velocity was a mean of 45 $\mathrm{cm} / \mathrm{s}$ in the milk vein (Hoegger 2006, Braun and Hoegger 2007), $55 \mathrm{~cm} / \mathrm{s}$ 
(Hoegger 2006) to $65 \mathrm{~cm} / \mathrm{s}$ (Föhn 1992, Braun and Föhn 2005) in the jugular vein and $90 \mathrm{~cm} / \mathrm{s}$ in the musculophrenic vein. Although the diameter of the jugular vein increased and its blood flow velocity decreased after administration of xylazine, these effects were only slight and not significant in the musculophrenic and milk veins. Further studies are needed to determine whether right-sided heart failure and inflammation of the diaphragm secondary to traumatic reticuloperitonitis affect the morphology and blood flow velocity of the musculophrenic vein. 
Table 1 : Mean and sd of various measurements with B-mode and Doppler sonography of the musculophrenic vein in 29 healthy cows

\begin{tabular}{l|c|c|c|c}
\hline Variable & $\begin{array}{l}\text { Before sedation } \\
(\text { mean }[\mathrm{sd}])\end{array}$ & $\begin{array}{l}\text { After sedation } \\
(\text { mean }[\mathrm{sd}])\end{array}$ & $\begin{array}{l}\text { Variation before } \\
\text { sedation }\end{array}$ & $\begin{array}{l}\text { Variation after } \\
\text { sedation }\end{array}$ \\
\hline Diameter of vein $(\mathrm{cm})$ & $0.7[0.2]$ & $0.8[0.2]$ & $0.5-1.1$ & $0.4-1.2$ \\
\hline $\begin{array}{l}\text { Distance between Doppler } \\
\text { measuring point and body } \\
\text { surface }(\mathrm{cm})\end{array}$ & $2.1[0.5]$ & $2.0[0.5]$ & $1.5-2.7$ & $1.3-2.5$ \\
\hline $\begin{array}{l}\text { Maximum flow velocity } \\
(\mathrm{cm} / \mathrm{s})\end{array}$ & $90.2[38.6]$ & $81.3[30.0]$ & $48-138$ & $48-129$ \\
\hline $\begin{array}{l}\text { Mean flow velocity }(\mathrm{cm} / \mathrm{s}) \\
\text { Minimum flow velocity }\end{array}$ & $60.4[22.3]$ & $49.9[19.4]$ & $29-88$ & $27-79$ \\
\hline$(\mathrm{cm} / \mathrm{s})$ & $41.4[24.2]$ & $31.1[23.2]$ & $14-83$ & $9-51$ \\
\hline
\end{tabular}




\section{References}

BRAUN, U. \& GÖTZ, M. (1994) Ultrasonography of the reticulum in cows. American Journal of Veterinary Research 55, 325-332

BRAUN, U. \& FÖHN, J. (2005) Duplex ultrasonography of the common carotid artery and external jugular vein of cows. American Journal of Veterinary Research 66, 962-965

BRAUN, U. \& HOEGGER, R. (2007) Colour-Doppler sonography of the milk vein in 29 healthy cows. Submitted for publication

FÖHN, J. (1992) Sonographische und duplexsonographische Untersuchungen an der ventralen Halsregion des Rindes. Dr Med Vet Dissertation, Faculty of Veterinary Medicine, University of Zurich

GÖTZ, M. (1992) Sonographische Untersuchungen an der Haube des Rindes. DrMedVet Thesis, Faculty of Veterinary Medicine, University of Zurich. HENDRICKX , P., ROTH, U., BRASSEL, F., TAUBERT, K., RANKE, C. \& WAGNER, H. (1990) Phantomuntersuchungen zur Wertigkeit der farbkodierten Doppler-Sonographie bei der arteriellen Verschlusskrankheit der unteren Extremitäten. Fortschritte auf dem Gebiet der Röntgenstrahlen und der bildgebenden Verfahren 152, 421-424

HOEGGER, R. (2006) Farbdoppler Untersuchungen an Arterien und Venen des

Rindes. Dr Med Vet Dissertation, Vetsuisse Faculty, University of Zurich RANKE, C., HENDRICKX, P., BRASSEL, F., ROTH, U., CREUTZIG, A. \& ALEXANDER, K. (1990) Duplexsonographie: Genauigkeit, Reproduzierbarkeit und Fehlermöglichkeiten. Deutsche medizinische Wochenschrift 115, 528-533 WIDDER, B. und GOERTLER, M. (2004) Doppler- und Duplexsonographie der hirnversorgenden Arterien. Berlin, Heidelberg, Springer 